\title{
Telomere targeting approaches in cancer: over the length
} maintenance.

\author{
Eleonora Vertecchi ${ }^{1}$, Angela Rizzo ${ }^{2}$ and Erica Salvati ${ }^{1}$ *
}

${ }^{1}$ Institute of Molecular Biology and Pathology, National Research Council, Rome, Italy, c/o Department of Biology and Biotechnology, Sapienza University of Rome, Via degli Apuli 4, 00185 Rome, Italy.

Oncogenomic and Epigenetic Unit, IRCCS Regina Elena National Cancer Institute, Via Elio Chianesi 53, 00144 Rome, Italy

* Correspondence: erica.salvati@cnr.it

Abstract: Telomeres are crucial structures that preserve genome stability. Their progressive erosion over rounds of DNA duplication determines senescence of cells and organisms. Telomere length homeostasis is critical for cancer development then telomere maintenance mechanisms are established targets in cancer treatment. Besides telomere elongation, telomere's dysfunction impinges on intracellular signalling pathways, in particular DNA damage signalling and repair affecting cancer cell survival and proliferation. This review summarizes and discusses about the recent findings in anti-cancer drug development targeting different "telosome" components. 
Citation: Lastname, F.; Lastname, F.; Lastname, F. Title. Int. J. Mol. Sci. 2021, 22, x.

https://doi.org/10.3390/xxxxx

Academic Editor: Firstname Last-

name

Received: date

Accepted: date

Published: date

Publisher's Note: MDPI stays neutral with regard to jurisdictional claims in published maps and institutional affiliations.

Copyright: (C) 2021 by the authors. Submitted for possible open access publication under the terms and conditions of the Creative Commons Attribution (CC BY) license

(http://creativecommons.org/license s/by/4.0/).
1. Telomeres: evolution and length maintenance in aging and cancer.

Telomeres are specialized structures at chromosome ends deputed to protection and preservation of genetic information through cell duplication. Evolutionarily, telomeres are deemed to originate from introns recombination in circular DNA molecules, generating non-coding extremities[1]. Telomere repeats are species-specific G-C rich conserved sequences, (in human 5'-TTAGGG- 3') terminating with a G-rich (or in some species both G and C-rich) overhang[2]. The extremities of linear DNA molecules fail to be completely replicated by the DNA replication machinery, then, the presence of non-coding DNA at the extremities overcame the progressive loss of terminal sequences at each cell division round [3]. Since telomeres are lost with cell duplication, several studies were conducted to find correlations between telomere length and age, showing that telomere length is reduced over age [4]. Moreover, genetic defects reducing the inherited telomere length affect offspring lifespan and the self-renewal capacity of tissues due to stem cell exhaustion.[4] Telomere shortening is accompanied by the exhibition of DNA damage response markers, that individuate dysfunctional telomeres and trigger replicative senescence.[5] Mounting evidence supports a role for telomere's dysfunction also in human ageing-related pathologies [6]. Recently, an extensive analysis of telomere length (TL) in different human tissue types and individuals clearly showed a significant correlation of TL with genetic background, gene expression and ageing. Furthermore, telomere shortening was shown to mediate aging related gene expression. In fact, telomeres can be shortened by exogenous mechanisms as oxidative stress or inflammation, and a "short-telomeres" genetic signature can drive the exhibition of aging cell phenotypes. [7] Some cells, like gametes, cancer cells and stem cells, have developed a successful strategy to overcome the replication end problem through the expression of telomerase, a ribonucleoprotein involved in counteracting the shortening of telomeric ends. Telomerase expression is strictly controlled throughout human development: if embryo stem cells have a high activity of telomerase, in the most adult somatic cells telomerase is not detectable, with the exception of lymphocytes in bone marrow and peripheral blood and a cluster of epithelial cells in the skin, hair follicle, endometrium and gastrointestinal tract [8] [9] [10]. Some human tumors (10-20\% approximately) do not express telomerase and restore telomere length through alternative mechanism (ALT). Preference for ALT or telomerase activation may depend on the histological origin of the tumor, the mutational background or epigenetic mechanisms, and confers different characteristics to the cancer type in terms of prognosis and response to treatments. [11]There is also a residual number of human tumors where any detectable mechanism of telomere elongation was found (Telomere length maintenance deficient, TLM-), however, in that tumor cells with ever-shorter telomeres, initial telomere length was 
sufficient to guarantee for cell replication capacity. This demonstrates that prevention of telomere shortening is not required for oncogenesis.[12]

\section{Telomere's structure}

2.1 The Shelterin complex.

In mammals, telomere repeats are bound by a specific complex composed by six factors: TRF1 and TRF2 (Telomere Repeat binding Factors 1 and 2) directly bind to the telomeric DNA duplex as homodimers, POT1 (Protection of Telomeres 1) binds the G-rich single strand over-hang, and TPP1, TIN2 and Rap1 act as a bridge among the shelterin factors, holding fast the structure of the complex itself [13] (Figure 1). The shelterin complex covers the telomeric DNA and impede the activation of repair and recombination mechanisms allowing the cell to discriminate between natural extremities and DNA lesions. The members of the shelterin complex have distinct function involved in different DDR signaling and repair pathways [14] and affect telomere elongation mechanisms [8].

When telomeres undergo massive erosion due to replicative senescence or other stresses, the shelterin complex is less abundant to chromosomal extremities, and DDR is de-repressed leading to cell arrest and senescence[15]. DDR at eroded and/or unprotected telomeres, failing to mask linear DNA termination, activates a signaling cascade recruiting Homologous Recombination and canonical or non-canonical Non-Homologous End Joining machineries. These telomeres, considered as dysfunctional, encounter recombination events giving rise to telomeric fusions or loss of telomeric repeats.

\subsection{Telomeric DNA and secondary structures}

Telomere protection relies on the presence of a terminal cap-like structure called T-loop that is stabilized by the shelterin complex (principally TRF2). The presence of t-loops at telomere ends, was hypothesized almost twenty years ago given the presence of a single stranded overhang with sequence complementarity to telomere duplex, and successively observed in-vitro and in-vivo by atomic force and super resolution microscopy, [16][17].. More recently, it has been demonstrated that t-loop formation is also stimulated by telomere transcription[18]. For longtime, in fact, telomeres have been considered as silent chromatin territories. Recently, it has been found that telomeres are transcribed into long non-

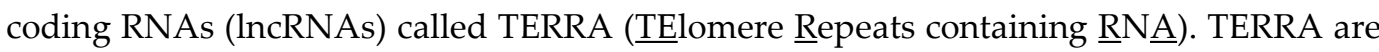
transcribed from subtelomeric promoters, they are regulated by the methylated state of subtelomeres and are strongly upregulated in cells with alternative telomere-lengthening mechanisms (ALT). They remain associated to telomeric chromatin forming R-loops which increase the predisposition to hyper-recombination of ALT telomeres[19]. Upon DNA damage at telomeres, damage induced long noncoding RNAs (dilncRNAs) are transcribed bidirectionally starting from the DNA lesions. These RNAs are precursor of small non 
coding RNAs (named DDRNAs) and mediate the efficient transduction of signaling cascade driving cell arrest and repair[20][21]. Telomere damage induced transcription was shown to be a crucial for mediating of the expression of senescence associated cell phenotypes[22].

Telomeres are difficult to replicate regions, being constituted by heterochromatin and prone to fold into secondary structures like G-quadruplexes, t-loop, I-motifs[23]. In addition, the presence of long non-coding RNA transcribed from subtelomeric promoters, that stably interact with DNA duplex forming R-loops, [24] makes these chromosome fields enriched of topological enzymes necessary to assist replication, transcription, histone modification. Telomeres are indeed considered as "difficult to repair" chromatin, that consequently accumulate irreparable DNA damage causing senescence and aging[25]. In this regard, mutations affecting helicase, topoisomerase, histone acetylation and methylation cause telomere dysfunction and consequently aging associated phenotypes.
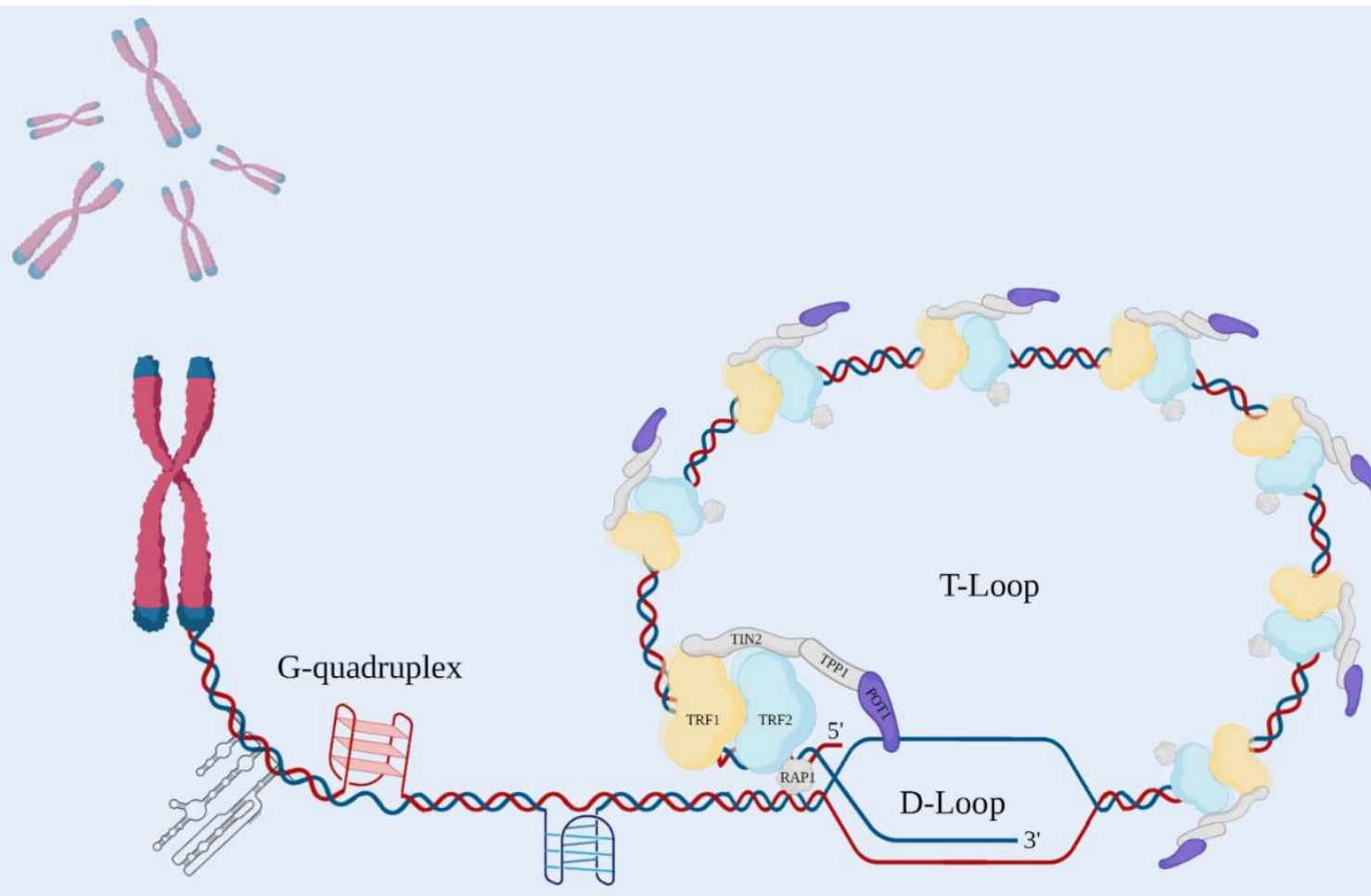

IncRNA TERRAs

I-motif

Nucleus

Figure 1. Molecular targets at telomeres 
In precancerous cells, bearing cell cycle checkpoints failure, shortened telomere instability generates mis-segregation and chromosome breakage during mitosis, giving rise to secondary rearrangements that fuel global genetic instability[26]. Thus, telomere protection is considered a tumor suppressive factor. Otherwise, telomere length maintenance is a prerequisite for cancer development since telomere attrition during cell divisions must be buffered in actively replicating cancer cells, to maintain an unlimited proliferative potential. [27] Telomere maintenance mechanisms are in fact considered a hallmark of cancer [28], although recently, some papers reported the existence of human tumors without any detectable telomere elongation mechanism.[12] Moreover, a pan-cancer genomics study detected hTERT (the catalytic subunit of telomerase holoenzyme) expression in $\sim 75 \%$ of tumor samples. In these samples, telomerase reactivation occurred by point mutation (31\%) or methylation (53\%) in the hTERT promoter.[29] Telomerase enzymatic activity is directly correlated with cancer cell proliferation and stemness [30] and reactivation mechanisms include also gene amplification, rearrangements of gene locus. [31] Activation of telomerase coincides with other pro-oncogenes changes in adult somatic cells in the early steps of cancer development [28]. The pro-oncogenic activity of telomerase is not restricted to telomere elongation but involves interactions between hTERT subunit and signaling pathways controlling cell survival and transformation like c-myc, WNT/ßcatenin, NF-kB, however, the number of identified cross-talks between hTERT and intracellular signaling is constantly growing. [32] Nevertheless, current anti-telomerase approaches, targets the telomere elongation activity only, being directed towards the catalytic site of hTERT or the RNA template.

Beside telomerase and other TLM mechanisms, other telomeric proteins are found mutated or deregulated in cancer. POT1(Protection of Telomeres 1) is an essential component for telomere stability. [33] It binds both the ss and the dsDNA at telomeres directly or interacting with other shelterins (namely TPP1 and TRF1) respectively; it counteracts G-quadruplex formation [34] and attenuates ATR driven DDR.[35] Germline and sporadic mutation of POT1 are associated with different human cancers. POT1 is frequently mutated in aggressive forms of chronic lymphocytic leukemia. Furthermore, germline POT1 mutations have been shown to underlie a number of hereditary familial cancer syndromes involving CLL, glioma, melanoma and colorectal cancer and angiosarcoma. [36]. Telomere binding proteins are overexpressed in cancer, this is not simply explained by telomere reelongation, in fact, some aggressive cancers present an unbalance between telomere length and telomere binding protein expression, which can be at the basis of the presence of dysfunctional telomeres generating genome instability [37] [38]. TRF1 is over-expressed in early stages of pancreas tumorigenesis and glioblastoma progression in mouse models [39] and TRF1 SNPs were found associated with increased risk of skin cancer in human[40]. 
TRF2 is upregulated in several human cancers, it is involved in immune escape and angiogenesis through different pathways [41][42][43][44]. Alterations of the shelterin complex were recently assessed in 9125 tumor samples in 33 different human cancers. TRF1 and POT1 amplification and TRF2-RAP1-TPP1 co-amplification/deletion were found associated with cancer progression defining broad molecular signatures linked to several intracellular pathways involved in oncogenesis[45]. Data collected in endometrial cancer patients suggest instead an inverse correlation between TERRA expression and cancer progression[46].

\section{Targeting approaches against telomere components}

\subsection{Telomeric DNA secondary structures}

4.1.1 G-quadruplex. Telomeric DNA is considered as a preferential target for G-quadruplex ligands and in the last two decades several molecules belonging to this class of compounds, have shown the capacity to affect both length and structure maintenance in a dose dependent manner.[47][48] G-quadruplexes were initially thought to act by binding and sequestering the G-overhang from telomerase elongation. In agreement with this, some Gquadruplex binders induced telomere shortening across population doublings. [49] In addition, G-quadruplex stabilization can displace shelterin proteins (TRF2 and POT1) and induce a rapid DNA damage response triggering cell death. [50]G-quadruplex stabilization also stabilizes DNA-loops forming in the telomeric duplex at the G-rich strand during replication, inducing replication dependent damage, or transcriptional loops (R-loops) generating transcription/translation conflicts. [51] The synergistic effect of G-quadruplex with clinically employed drugs like camptothecins and PARP inhibitors, as well as ionizing radiations, make this class of compounds still interesting and deserving investigation, although none of this compound has been approved yet for clinical use. Notably, the CX5461, the RNA polymerase I inhibitor currently employed for the treatment of XY, has been discovered to bind G-quadruplex and to target more effectively BRCA mutated cells, and this last characteristic is in common with Pyridostatin, another G-quadruplex ligand with excellent anticancer properties.[52] [53] The most studied G-quadruplex ligands with telomere-targeting properties are summarized in table 1. In addition to this list of compounds, virtual-screening and mid-high throughput screening studies have revealed other classes of compounds emerging from small molecules or natural compounds libraries, with the capability of targeting telomeres and inducing a DDR response. Thus confirming that the G-quadruplex interactive compounds are a continue source of new molecules for medicinal chemistry in anti-cancer application.[54][55][56][57][58][59]

The C-rich strand of telomeres is known to form quadruplex structures in- vitro and invitro, namely i-motifs, that can coexist with G-quadruplexes or be mutually exclusive depending on the context. Some quadruplex ligands are specific for G or C-quadruplexes while other are selective (Table 1). [60][61] i-motifs binding induces telomere damage and 
cell death in cancer cells as well as G-quadruplex ligands and the rational design of new imotifs ligand with higher specificity is a highly productive branch of drug discovery currently.

\subsection{Shelterins}

4.2.1 TRF1 was found upregulated in glioblastoma in human specimen and in mouse models and its downregulation impact on tumor progression validating TRF1 as a target in glioblastoma treatment. [62] Moreover, previous results showed that TRF1 inhibition impaired growth of K-Ras induced lung cancer in p53 deficient mice without significant side effects [63] [64]PI3K and AKT chemical inhibitors reduce TRF1 telomeric foci and lead to increased telomeric DNA damage and fragility sinceTRF1 is a phosphorylation target of AKT and these modifications regulate TRF1 protein stability and TRF1 binding to telomeric DNA [65][66]. In addition, TRF1 was found to be phosphorylated by multiple kinases involved in cell signaling pathway (ERK2, bRaf, mTOR) and consequently it is targeted by specific kinase inhibitors from an FDA approved library. [67]

4.2.2 TRF2 has been implicated in several cancer related pathways such as immune escape[68][69] and angiogenesis control through different mechanisms[44][70]. Since TRF2 is overexpressed in different human cancer types and in some circumstances high levels correlate with drug resistance, it has been widely proposed as target for cancer therapy. Targeting strategies currently under development consist in peptides disrupting TRF2 protein-protein interactions. APOD peptide, has been designed to mimic the TRF2 interacting domain of the exonuclease Apollo. This peptide has been shown to induce DDR and cell death, inhibiting TRF2 mediated recruitment of enzymes necessary for DNA metabolism[71]. On the basis of this first evidence, other authors reported the development of cyclic peptides with the same target[72][73]. TRF2 is known to undergo a series of posttranslational modifications that regulate protein stability such as phosphorylation, SUMOylation, acetylation, deacetylation, ubiquitination, and Poly (ADP-ribose)ylation. [74] [75][76][77] [78] [79] This mechanistical insights into TRF2 protein stability regulation, provide the basis for indirect targeting of TRF2. SIRT6 deacetylases, for example, is known to stimulate TRF2 degradation, then its pharmacological activator could work as a TRF2 targeting agent. Extracellular signal-regulated kinases ERK1/2 regulate TRF2 phosphorylation and stability[80], consequently drugs interfering with ERK1/2 signalling could also exert a role in TRF2 targeting. A recent drug screening revealed that at least two FDAapproved compounds (AR-A014418 and alexidine-2HCl, an inhibitor of Wnt pathway and a mitochondria-targeting agent respectively) are able to induce anti-proliferative effects by downregulating TRF2 and suppressing its pro-angiogenic and immunoescaping effects. [81] While the first compound presumably exerts its effect by acting on TRF2 promoter (which is regulated by the Wnt pathway [82]), the second one acts with unexplained mechanisms. In addition, Curcusone $C$, another small molecule with anti-cancer property, binds to TRF2 and block its binding to DNA inducing a DDR and cell death.[83] Finally, 
chemotherapeutic drugs such as Arsencic trioxide (As2O3), clinically employed in the treatment of acute promyelocytic leukemia (APL), or the TopoI camptothecin, were shown to downregulate TRF2 levels.[84][85]

4.2.3 POT1 is the most recurrently mutated gene of shelterin complex in cancer. Indeed, mutations affecting the interaction domains of POT1 to the ssDNA or TPP1 are associated with multiple types of human malignancies such as glioma, familial melanoma, mantle cell lymphoma, chronic lymphocytic leukemia and cardiac angiosarcoma. [36]In addition, it is frequently upregulated in therapeutic and radiation-resistant cell lines. This makes it an attractive target as therapeutic intervention against POT1-related cancers. The first attempt to identify specific POT1 inhibitors comes from a high-throughput time-resolved fluorescence resonance energy transfer (TR-FRET) screen for agents hampering POT1/ssDNA interaction. The yielded compound, the bis-azo dye Congo red (CR), was able to competitively inhibit POT1 binding to telomeric DNA in vitro. [86]Recently, a virtual highthroughput screening (vHTS), designed against a ZINC library, has led to the identification of two selected natural compounds as promising inhibitors of POT1, which deserve to be further exploited as lead to develop potent and selective molecules against POT1. [87]

\subsection{TERRA}

TERRAs have an established role in telomere protection and genome integrity (recently revised in [88]). Growing evidence not surprisingly attributes an anti-cancer role to TERRA [45][46][89], however its targeting could be detrimental especially for ALT cancer cells[90]. TERRA is prone to fold into G-quadruplex structures that can be bound and stabilized influencing intracellular TERRA levels and localization. TERRA transcription was shown to be affected directly by acridine derivatives [91] and indirectly by Quindoline derivatives acting on TRF2 levels which in turn regulates TERRA expression [92]. TERRA stabilization could also occur as a consequence of sequestering from degradation upon direct binding by G-quadruplex ligands [90].

\begin{tabular}{|c|c|c|c|c|c|}
\hline Agent & $\begin{array}{c}\text { Telomeric } \\
\text { targets }\end{array}$ & Mechanism & $\begin{array}{l}\text { Synergism/syn- } \\
\text { thetic lethality }\end{array}$ & $\begin{array}{l}\text { Anti-cancer } \\
\text { effect }\end{array}$ & Ref. \\
\hline $\begin{array}{l}\text { RHPS4 } \\
\text { and derivatives }\end{array}$ & $\begin{array}{l}\text { G-quadruplex } \\
\text { i-motifs }\end{array}$ & $\begin{array}{l}\text { TRF2 POT1 delo- } \\
\text { calization } \\
\text { Replication pertur- } \\
\text { bation } \\
\text { DDR activation }\end{array}$ & $\begin{array}{l}\text { Camptotecins } \\
\text { PARPi } \\
\text { Ionizing radiations }\end{array}$ & $\begin{array}{l}\text { ALT cells } \\
\text { Glioblastoma } \\
\text { Colorectal cancer }\end{array}$ & $\begin{array}{l}{[93][94]} \\
{[95][96]} \\
{[97][98]} \\
{[99]}\end{array}$ \\
\hline BRACO19 & $\begin{array}{l}\text { G-quadruplex } \\
\text { i-motifs }\end{array}$ & $\begin{array}{l}\text { T-loop disassembly } \\
\text { POT1 downregula- } \\
\text { tion } \\
\text { DDR activation }\end{array}$ & Cis platinum & $\begin{array}{l}\text { Lung cancer } \\
\text { Breast cancer } \\
\text { Glioblastoma }\end{array}$ & $\begin{array}{l}{[100][101]} \\
{[102]}\end{array}$ \\
\hline
\end{tabular}




\begin{tabular}{|c|c|c|c|c|c|}
\hline Telomestatin & G-quadruplex & $\begin{array}{l}\text { POT1 and TRF2 } \\
\text { displacement } \\
\text { G-overhang loss } \\
\text { DDR activation }\end{array}$ & $\begin{array}{l}\text { Imatinib } \\
\text { Vincristin } \\
\text { Ionizing radiations }\end{array}$ & $\begin{array}{l}\text { Glioma } \\
\text { Neuroblastoma } \\
\text { Sarcoma } \\
\text { ALT cells } \\
\text { Leukemia }\end{array}$ & $\begin{array}{l}{[103][104]} \\
{[105][105]} \\
{[106][107]} \\
{[108]}\end{array}$ \\
\hline $\begin{array}{l}\text { Naphtalene } \\
\text { diimmides }\end{array}$ & G-quadruplex & DDR activation & Ionizing radiations & $\begin{array}{l}\text { Glioma } \\
\text { Pancreatic cancer }\end{array}$ & $\begin{array}{l}{[109][110]} \\
{[111][112]} \\
{[113]}\end{array}$ \\
\hline Pyridostatin & $\begin{array}{l}\text { G-quadruplex } \\
\text { i-motifs }\end{array}$ & DDR activation & BRCA1/2 mut & $\begin{array}{l}\text { Colon cancer } \\
\text { Renal cancer }\end{array}$ & {$[114][53]$} \\
\hline $\begin{array}{l}\text { Perilene coro- } \\
\text { nene derivatives }\end{array}$ & G-quadruplex & DDR activation & N.A. & Colorectal cancer & [115][116] \\
\hline AKT inhibitors & TRF1 & $\begin{array}{l}\text { TRF1 downregula- } \\
\text { tion }\end{array}$ & N.A. & Glioblastoma & {$[65][67]$} \\
\hline $\begin{array}{l}\text { APO D41 pep- } \\
\text { tides }\end{array}$ & TRF2 & DDR activation & N.A. & N.A. & [71] \\
\hline Curcusone C & TRF2 & DDR induction & N.A. & $\begin{array}{l}\text { Ovarian cancer } \\
\text { Endometrial cancer }\end{array}$ & [83] \\
\hline $\begin{array}{l}\text { Quindoline de- } \\
\text { rivatives }\end{array}$ & G-quadruplex & $\begin{array}{l}\text { TRF2 delocaliza- } \\
\text { tion } \\
\text { TERRA downregu- } \\
\text { lation }\end{array}$ & N.A. & N.A. & [117] \\
\hline BPBA & G-quadruplex & $\begin{array}{l}\text { TERRA stabiliza- } \\
\text { tion }\end{array}$ & N.A. & ALT cells & [90] \\
\hline
\end{tabular}

Table 1. Summary of compounds with in-cellulo assessed telomere-targeting activity and mechanism of action.

\section{Conclusions}

Telomeres are nucleoprotein complexes involved in genome stability, cell proliferation, cancer predisposition and aging. Their homeostasis is subjected to a complex interaction network including multiple regulation levels. Beside telomerase inhibition and consequent telomere attrition, telomere targeting gather different approaches directed toward DNA, RNA, and proteins. Telomere's dysfunction, intended as DNA damage response activated at telomeres, can trigger genetic instability and cell death in tumor cells, giving the rational for pursue investigating in telomere targeting approaches in cancer as single agents and in rational based combinations with standard therapeutics.

Author Contributions: All authors have read and agreed to the published version of the manuscript.

Funding: This research was funded by AIRC \#17121 to E.S.

Conflicts of Interest: "The authors declare no conflict of interest."

\section{References}

[1] T. De Lange, “T-loops and the origin of telomeres," Nat. Rev. Mol. Cell Biol., vol. 5, no. 4, pp. 323-329, 2004, doi: 
[2] H. Xin et al., "TPP1 is a homologue of ciliate TEBP- $\beta$ and interacts with POT1 to recruit telomerase," Nature, vol. 445, no. 7127, pp. 559-562, 2007, doi: 10.1038/nature05469.

[3] R. J. Wellinger, “In the end, what's the problem?," Mol. Cell, vol. 53, no. 6, pp. 855-856, 2014, doi: 10.1016/j.molcel.2014.03.008.

[4] G. Aubert and P. M. Lansdorp, “Telomeres and aging," Physiological Reviews, vol. 88, no. 2. pp. 557-579, Apr2008, doi: 10.1152/physrev.00026.2007.

[5] d'Adda di F. F et al., "A DNA damage checkpoint response in telomere-initiated senescence," Nature, vol. 426, no. 6963, pp. 194-198, Nov. 2003, doi: 10.1038/NATURE02118.

[6] D. Chakravarti, K. A. LaBella, and R. A. DePinho, “Telomeres: history, health, and hallmarks of aging.,” Cell, Jan. 2021, doi: 10.1016/j.cell.2020.12.028.

[7] K. Demanelis et al., “Determinants of telomere length across human tissues," doi: 10.1126/science.aaz6876.

[8] S. Hanaoka, A. Nagadoi, and Y. Nishimura, "Comparison between TRF2 and TRF1 of their telomeric DNAbound structures and DNA-binding activities," Protein Sci., vol. 14, no. 1, pp. 119-130, 2009, doi: 10.1110/ps.04983705.

[9] A. L. Slusher, J. J. J. Kim, and A. T. Ludlow, "The role of alternative rna splicing in the regulation of htert, telomerase, and telomeres: Implications for cancer therapeutics," Cancers (Basel)., vol. 12, no. 6, pp. 1-16, 2020, doi: 10.3390/cancers12061514.

[10] K. Collins and J. R. Mitchell, “Telomerase in the human organism,” Oncogene, vol. 21, no. 4 REV. ISS. 1, pp. 564579, 2002, doi: 10.1038/sj/onc/1205083.

[11] L. Pompili, C. Leonetti, A. Biroccio, and E. Salvati, "Diagnosis and treatment of ALT tumors: Is Trabectedin a new therapeutic option?," J. Exp. Clin. Cancer Res., vol. 36, no. 1, 2017, doi: 10.1186/s13046-017-0657-3.

[12] D. RA et al., "Extensive Proliferation of Human Cancer Cells with Ever-Shorter Telomeres," Cell Rep., vol. 19, no. 12, pp. 2544-2556, Jun. 2017, doi: 10.1016/J.CELREP.2017.05.087.

[13] E. M. Smith, D. F. Pendlebury, and J. Nandakumar, "Structural biology of telomeres and telomerase," Cellular and Molecular Life Sciences, vol. 77, no. 1. 2020, doi: 10.1007/s00018-019-03369-x.

[14] T. De Lange, "Shelterin: The protein complex that shapes and safeguards human telomeres," Genes Dev., vol. 19, no. 18, pp. 2100-2110, 2005, doi: 10.1101/gad.1346005.

[15] A. Sfeir and T. De Lange, "Removal of shelterin reveals the telomere end-protection problem," Science (80-. )., vol. 336, no. 6081, pp. 593-597, May 2012, doi: 10.1126/science.1218498.

[16] L. Tomáška, A. J. Cesare, T. M. AlTurki, and J. D. Griffith, “Twenty years of t-loops: A case study for the importance of collaboration in molecular biology," DNA Repair (Amst)., vol. 94, no. June, p. 102901, 2020, doi: 10.1016/j.dnarep.2020.102901.

[17] P. Ruis and S. J. Boulton, "The end protection problem - an unexpected twist in the tail," Genes Dev., vol. 35, no. 1-2, pp. 1-21, Jan. 2021, doi: 10.1101/gad.344044.120.

[18] A. Kar, S. Willcox, and J. D. Griffith, "Transcription of telomeric DNA leads to high levels of homologous recombination and t-loops," Nucleic Acids Res., vol. 44, no. 19, pp. 9369-9380, Nov. 2016, doi: 10.1093/nar/gkw779.

[19] A. Barral and J. Déjardin, “Telomeric Chromatin and TERRA," Journal of Molecular Biology, vol. 432, no. 15. Academic Press, pp. 4244-4256, 10-Jul-2020, doi: 10.1016/j.jmb.2020.03.003.

[20] F. Rossiello et al., "DNA damage response inhibition at dysfunctional telomeres by modulation of telomeric DNA damage response RNAs," Nat. Commun., vol. 8, Feb. 2017, doi: 10.1038/ncomms13980.

[21] F. Michelini et al., "Damage-induced lncRNAs control the DNA damage response through interaction with DDRNAs at individual double-strand breaks," Nat. Cell Biol., vol. 19, no. 12, pp. 1400-1411, Nov. 2017, doi: 
10.1038/ncb3643.

[22] J. Aguado et al., "Inhibition of DNA damage response at telomeres improves the detrimental phenotypes of Hutchinson-Gilford Progeria Syndrome," Nat. Commun., vol. 10, no. 1, Dec. 2019, doi: 10.1038/s41467-019-130183.

[23] E. Gilson and V. Géli, "How telomeres are replicated," Nature Reviews Molecular Cell Biology, vol. 8, no. 10. pp. 825-838, Oct-2007, doi: 10.1038/nrm2259.

[24] E. Cusanelli and P. Chartrand, "Telomeric repeat-containing RNA TERRA: A noncoding RNA connecting telomere biology to genome integrity," Front. Genet., vol. 6, no. MAR, p. 143, 2015, doi: 10.3389/fgene.2015.00143.

[25] F. Rossiello, U. Herbig, M. P. Longhese, M. Fumagalli, and F. d'Adda di Fagagna, "Irreparable telomeric DNA damage and persistent DDR signalling as a shared causative mechanism of cellular senescence and ageing," Current Opinion in Genetics and Development, vol. 26. Elsevier Ltd, pp. 89-95, 2014, doi: 10.1016/j.gde.2014.06.009.

[26] K. Cleal and D. M. Baird, "Catastrophic Endgames: Emerging Mechanisms of Telomere-Driven Genomic Instability," Trends in Genetics, vol. 36, no. 5. Elsevier Ltd, pp. 347-359, 01-May-2020, doi: 10.1016/j.tig.2020.02.001.

[27] D. Hanahan and R. A. Weinberg, “The hallmarks of cancer," Cell, vol. 100, no. 1. Cell, pp. 57-70, 07-Jan-2000, doi: 10.1016/S0092-8674(00)81683-9.

[28] J. W. Shay, "Role of telomeres and telomerase in aging and cancer," Cancer Discov., vol. 6, no. 6, pp. 584-593, 2016, doi: 10.1158/2159-8290.CD-16-0062.

[29] F. P. Barthel et al., "Systematic analysis of telomere length and somatic alterations in 31 cancer types," Nat. Genet., vol. 49, no. 3, pp. 349-357, Mar. 2017, doi: 10.1038/ng.3781.

[30] N. Noureen et al., "Integrated analysis of telomerase enzymatic activity unravels an association with cancer stemness and proliferation.," Nat. Commun., vol. 12, no. 1, p. 139, Dec. 2021, doi: 10.1038/s41467-020-20474-9.

[31] S. G. Fernandes et al., "Role of telomeres and telomeric proteins in human malignancies and their therapeutic potential," Cancers, vol. 12, no. 7. MDPI AG, pp. 1-38, 01-Jul-2020, doi: 10.3390/cancers12071901.

[32] A. Pestana, J. Vinagre, M. Sobrinho-Simões, and P. Soares, "TERT biology and function in cancer: Beyond immortalisation," Journal of Molecular Endocrinology, vol. 58, no. 2. BioScientifica Ltd., pp. R129-R146, 01-Feb2017, doi: 10.1530/JME-16-0195.

[33] D. Hockemeyer, A. J. Sfeir, J. W. Shay, W. E. Wright, and T. de Lange, "POT1 protects telomeres from a transient DNA damage response and determines how human chromosomes end," EMBO J., vol. 24, no. 14, pp. 2667-2678, Jul. 2005, doi: 10.1038/sj.emboj.7600733.

[34] J. B. Chaires et al., "Human POT1 unfolds G-quadruplexes by conformational selection," Nucleic Acids Res., vol. 48, no. 9, pp. 4976-4991, May 2020, doi: 10.1093/nar/gkaa202.

[35] X. Guo et al., "Dysfunctional telomeres activate an ATM-ATR-dependent DNA damage response to suppress tumorigenesis," EMBO J., vol. 26, no. 22, p. 4709, Nov. 2007, doi: 10.1038/SJ.EMBOJ.7601893.

[36] Y. Wu, R. C. Poulos, and R. R. Reddel, "Role of pot1 in human cancer," Cancers (Basel)., vol. 12, no. 10, pp. 1-19, Oct. 2020, doi: 10.3390/cancers12102739.

[37] K. S. Butler, W. C. Hines, C. M. Heaphy, and J. K. Griffith, "Coordinate regulation between expression levels of telomere-binding proteins and telomere length in breast carcinomas," Cancer Med., vol. 1, no. 2, pp. 165-175, 2012, doi: 10.1002/cam4.14.

[38] M. Kirwan et al., "Dyskeratosis congenita and the DNA damage response," Br. J. Haematol., vol. 153, no. 5, pp. 634-643, 2011, doi: 10.1111/j.1365-2141.2011.08679.x.

[39] R. M. Marión et al., "Common Telomere Changes during In Vivo Reprogramming and Early Stages of Tumorigenesis," Stem Cell Reports, vol. 8, no. 2, pp. 460-475, Feb. 2017, doi: 10.1016/j.stemcr.2017.01.001. 
[40] H. Nan, A. A. Qureshi, J. Prescott, I. De Vivo, and J. Han, “Genetic variants in telomere-maintaining genes and skin cancer risk," Hum. Genet., vol. 129, no. 3, pp. 247-253, Mar. 2011, doi: 10.1007/s00439-010-0921-5.

[41] P. Zizza et al., "TRF2 positively regulates SULF2 expression increasing VEGF - A release and activity in tumor microenvironment," Nucleic Acids Res., vol. 47, no. 7, 2019, doi: 10.1093/nar/gkz041.

[42] J. Cherfils-Vicini et al., " Cancer cells induce immune escape via glycocalyx changes controlled by the telomeric protein TRF 2 ," EMBO J., vol. 38, no. 11, 2019, doi: 10.15252/embj.2018100012.

[43] A. Biroccio et al., "TRF2 inhibits a cell-extrinsic pathway through which natural killer cells eliminate cancer cells," Nat. Cell Biol., vol. 15, no. 7, 2013, doi: 10.1038/ncb2774.

[44] M. El Maï et al., "The telomeric protein TRF2 regulates angiogenesis by binding and activating the PDGFR $\beta$ promoter," Cell Rep., vol. 9, no. 3, pp. 1047-1060, 2014, doi: 10.1016/j.celrep.2014.09.038.

[45] "Pan-cancer analyses reveal regulation and clinical outcome association of the shelterin complex in cancer PubMed." [Online]. Available: https://pubmed.ncbi.nlm.nih.gov/33497432/. [Accessed: 05-Feb-2021].

[46] M. Adishesh et al., "Human endometrial carcinogenesis is associated with significant reduction in long noncoding rna, terra," Int. J. Mol. Sci., vol. 21, no. 22, pp. 1-13, Nov. 2020, doi: 10.3390/ijms21228686.

[47] G. Biffi, D. Tannahill, and S. Balasubramanian, "An intramolecular G-quadruplex structure is required for binding of telomeric repeat-containing RNA to the telomeric protein TRF2," J. Am. Chem. Soc., vol. 134, no. 29, pp. 11974-11976, Jul. 2012, doi: 10.1021/ja305734x.

[48] A. L. Moye et al., "Telomeric G-quadruplexes are a substrate and site of localization for humantelomerase," Nat. Commun., vol. 6, Jul. 2015, doi: 10.1038/NCOMMS8643.

[49] S. J, A. S, and B. S, “The Structure and Function of DNA G-Quadruplexes,” Trends Chem., vol. 2, no. 2, pp. 123136, Feb. 2020, doi: 10.1016/J.TRECHM.2019.07.002.

[50] E. Salvati et al., "Telomere damage induced by the G-quadruplex ligand RHPS4 has an antitumor effect," J. Clin. Invest., vol. 117, no. 11, pp. 3236-3247, Nov. 2007, doi: 10.1172/JCI32461.

[51] M. G, R. M, and C. G, “G-quadruplex-R-loop interactions and the mechanism of anticancer G-quadruplex binders," Nucleic Acids Res., vol. 48, no. 21, pp. 11942-11957, Dec. 2020, doi: 10.1093/NAR/GKAA944.

[52] H. Xu et al., "CX-5461 is a DNA G-quadruplex stabilizer with selective lethality in BRCA1/2 deficient tumours," Nat. Commun., vol. 8, Feb. 2017, doi: 10.1038/NCOMMS14432.

[53] J. Zimmer et al., "Targeting BRCA1 and BRCA2 Deficiencies with G-Quadruplex-Interacting Compounds.," Mol. Cell, vol. 61, no. 3, pp. 449-460, Feb. 2016, doi: 10.1016/j.molcel.2015.12.004.

[54] F. S. Di Leva et al., "Looking for efficient G-quadruplex ligands: evidence for selective stabilizing properties and telomere damage by drug-like molecules.," Biochim. Biophys. acta. Gen. Subj., vol. 10, no. 4, pp. 640-649, Apr. 2015, doi: 10.1002/cmdc.201402552.

[55] C. Platella et al., "Identification of Effective Anticancer G-Quadruplex-Targeting Chemotypes through the Exploration of a High Diversity Library of Natural Compounds.," Pharmaceutics, vol. 13, no. 10, Oct. 2021, doi: 10.3390/pharmaceutics13101611.

[56] J. Amato et al., "Tailoring a lead-like compound targeting multiple G-quadruplex structures.," Biochim. Biophys. acta. Gen. Subj., vol. 1861, no. 5 Pt B, pp. 1341-1352, May 2017, doi: 10.1016/j.ejmech.2018.11.058.

[57] A. Rizzo et al., "Erratum: Identification of novel RHPS4-derivative ligands with improved toxicological profiles and telomere-targeting activities (Journal of Experimental \&amp; Clinical Cancer Research (2014) 33 (81))," J. Exp. Clin. Cancer Res., vol. 34, no. 1, 2015, doi: 10.1186/s13046-014-0101-x.

[58] D. Musumeci et al., "Tandem application of ligand-based virtual screening and G4-OAS assay to identify novel G-quadruplex-targeting chemotypes," Biochim. Biophys. acta. Gen. Subj., vol. 1861, no. 5 Pt B, pp. 1341-1352, May 
2017, doi: 10.1016/J.BBAGEN.2017.01.024.

[59] B. Pagano et al., "Identification of novel interactors of human telomeric G-quadruplex DNA," Chem. Commun. (Camb)., vol. 51, no. 14, pp. 2964-2967, Feb. 2015, doi: 10.1039/C4CC07231F.

[60] A. Pagano et al., "Common G-Quadruplex Binding Agents Found to Interact With i-Motif-Forming DNA: Unexpected Multi-Target-Directed Compounds," Front. Chem., vol. 6, Jul. 2018, doi: 10.3389/FCHEM.2018.00281.

[61] O. Y. Fedoroff, A. Rangan, V. V. Chemeris, and L. H. Hurley, "Cationic porphyrins promote the formation of imotif DNA and bind peripherally by a nonintercalative mechanism," Biochemistry, vol. 39, no. 49, pp. 1508315090, Dec. 2000, doi: 10.1021/BI001528J.

[62] L. Bejarano et al., "Inhibition of TRF1 Telomere Protein Impairs Tumor Initiation and Progression in Glioblastoma Mouse Models and Patient-Derived Xenografts," Cancer Cell, vol. 32, no. 5, pp. 590-607.e4, Nov. 2017, doi: 10.1016/j.ccell.2017.10.006.

[63] M. García-Beccaria et al., " Therapeutic inhibition of TRF 1 impairs the growth of p53 -deficient K-Ras G12V induced lung cancer by induction of telomeric DNA damage ," EMBO Mol. Med., vol. 7, no. 7, pp. 930-949, Jul. 2015, doi: 10.15252/emmm.201404497.

[64] L. Bejarano, J. Louzame, J. J. Montero, D. Megías, J. M. Flores, and M. A. Blasco, "Safety of Whole-Body Abrogation of the TRF1 Shelterin Protein in Wild-Type and Cancer-Prone Mouse Models," iScience, vol. 19, pp. 572-585, Sep. 2019, doi: 10.1016/j.isci.2019.08.012.

[65] M.-P. M et al., "Modulation of telomere protection by the PI3K/AKT pathway," Nat. Commun., vol. 8, no. 1, Dec. 2017, doi: 10.1038/S41467-017-01329-2.

[66] R. Sánchez-Vázquez, P. Martínez, and M. A. Blasco, “AKT-dependent signaling of extracellular cues through telomeres impact on tumorigenesis," PLoS Genet., vol. 17, no. 3, Mar. 2021.

[67] L. Bejarano et al., "Multiple cancer pathways regulate telomere protection,” EMBO Mol. Med., vol. 11, no. 7, Jul. 2019, doi: 10.15252/EMMM.201910292.

[68] A. Biroccio et al., "TRF2 inhibits a cell-extrinsic pathway through which natural killer cells eliminate cancer cells," Nat. Cell Biol., vol. 15, no. 7, pp. 818-828, Jul. 2013, doi: 10.1038/ncb2774.

[69] J. Cherfils-Vicini et al., " Cancer cells induce immune escape via glycocalyx changes controlled by the telomeric protein TRF 2 ," EMBO J., vol. 38, no. 11, Jun. 2019, doi: 10.15252/embj.2018100012.

[70] P. Zizza et al., "TRF2 positively regulates SULF2 expression increasing VEGF - A release and activity in tumor microenvironment," Nucleic Acids Res., vol. 47, no. 7, pp. 3365-3382, Apr. 2019, doi: 10.1093/nar/gkz041.

[71] S. Di Maro et al., "Shading the TRF2 recruiting function: A new horizon in drug development," J. Am. Chem. Soc., vol. 136, no. 48, 2014, doi: 10.1021/ja5080773.

[72] T. Aramburu, S. Plucinsky, and E. Skordalakes, "POT1-TPP1 telomere length regulation and disease.," Comput. Struct. Biotechnol. J., vol. 18, pp. 1939-1946, Jan. 2020, doi: 10.1016/j.csbj.2020.06.040.

[73] X. Chen et al., "Cyclic Peptidic Mimetics of Apollo Peptides Targeting Telomeric Repeat Binding Factor 2 (TRF2) and Apollo Interaction," ACS Med. Chem. Lett., vol. 9, no. 5, pp. 507-511, 2018, doi: 10.1021/acsmedchemlett.8b00152.

[74] S. G et al., "CDK phosphorylation of TRF2 controls t-loop dynamics during the cell cycle," Nature, vol. 575, no. 7783, pp. 523-527, Nov. 2019, doi: 10.1038/S41586-019-1744-8.

[75] V. Subramanian, B. Rodemoyer, V. Shastri, L. J. Rasmussen, C. Desler, and K. H. Schmidt, “Bloom syndrome DNA helicase deficiency is associated with oxidative stress and mitochondrial network changes.," Sci. Rep., vol. 11, no. 1, p. 2157, Jan. 2021, doi: 10.1038/s41598-021-81075-0.

[76] G. Sarek, P. Marzec, P. Margalef, and S. J. Boulton, "Molecular basis of telomere dysfunction in human genetic 
diseases," Nat. Struct. Mol. Biol., vol. 22, no. 11, pp. 867-874, 2015, doi: 10.1038/nsmb.3093.

[77] Y. R. Her and I. K. Chung, "P300-mediated acetylation of TRF2 is required for maintaining functional telomeres," Nucleic Acids Res., vol. 41, no. 4, pp. 2267-2283, Feb. 2013, doi: 10.1093/NAR/GKS1354.

[78] A. Rizzo et al., "SIRT6 interacts with TRF2 and promotes its degradation in response to DNA damage," vol. 45, no. 4, pp. 1820-1834, 2017, doi: 10.1093/nar/gkw1202.

[79] F. Dantzer et al., "Functional Interaction between Poly(ADP-Ribose) Polymerase 2 (PARP-2) and TRF2: PARP Activity Negatively Regulates TRF2," Mol. Cell. Biol., vol. 24, no. 4, pp. 1595-1607, Feb. 2004, doi: 10.1128/MCB.24.4.1595-1607.2004.

[80] V. Picco, I. Coste, M. J. Giraud-Panis, T. Renno, E. Gilson, and G. Pagès, “ERK1/2/MAPK pathway-dependent regulation of the telomeric factor TRF2," Oncotarget, vol. 7, no. 29, pp. 46615-46627, 2016, doi: 10.18632/oncotarget.10316.

[81] E. M. M et al., "A Novel Screen for Expression Regulators of the Telomeric Protein TRF2 Identified Small Molecules That Impair TRF2 Dependent Immunosuppression and Tumor Growth," Cancers (Basel)., vol. 13, no. 12, Jun. 2021, doi: 10.3390/CANCERS13122998.

[82] D. I et al., "Telomere protection and TRF2 expression are enhanced by the canonical Wnt signalling pathway," EMBO Rep., vol. 14, no. 4, pp. 356-363, Apr. 2013, doi: 10.1038/EMBOR.2013.16.

[83] M. Wang et al., "Curcusone C induces telomeric DNA-damage response in cancer cells through inhibition of telomeric repeat factor 2," Biochim. Biophys. Acta - Proteins Proteomics, vol. 1865, no. 11, pp. 1372-1382, Nov. 2017, doi: 10.1016/J.BBAPAP.2017.08.022.

[84] Y. Cheng et al., "Arsenic trioxide inhibits glioma cell growth through induction of telomerase displacement and telomere dysfunction," Oncotarget, vol. 7, no. 11, p. 12682, Mar. 2016, doi: 10.18632/ONCOTARGET.7259.

[85] R. A et al., "SIRT6 interacts with TRF2 and promotes its degradation in response to DNA damage," Nucleic Acids Res., vol. 45, no. 4, pp. 1820-1834, Feb. 2017, doi: 10.1093/NAR/GKW1202.

[86] S. E. Altschuler, J. E. Croy, and D. S. Wuttke, "A small molecule inhibitor of Pot1 binding to telomeric DNA," Biochemistry, vol. 51, no. 40, pp. 7833-7845, Oct. 2012, doi: 10.1021/BI300365K.

[87] M. Amir et al., "Virtual high-throughput screening of natural compounds in-search of potential inhibitors for protection of telomeres 1 (POT1)," J. Biomol. Struct. Dyn., vol. 38, no. 15, pp. 4625-4634, Oct. 2020, doi: 10.1080/07391102.2019.1682052.

[88] B. N, O. P. C, and C. E, "The Emerging Roles of TERRA in Telomere Maintenance and Genome Stability," Cells, vol. 8, no. 3, p. 246, Mar. 2019, doi: 10.3390/CELLS8030246.

[89] H. Cao et al., "Noncoding telomeric repeat-containing RNA inhibits the progression of hepatocellular carcinoma by regulating telomerase-mediated telomere length," Cancer Sci., vol. 111, no. 8, pp. 2789-2802, Aug. 2020, doi: 10.1111/CAS.14442.

[90] M. S et al., "Targeting of Telomeric Repeat-Containing RNA G-Quadruplexes: From Screening to Biophysical and Biological Characterization of a New Hit Compound," Int. J. Mol. Sci., vol. 22, no. 19, Oct. 2021, doi: 10.3390/IJMS221910315.

[91] K. S et al., "Transcriptional regulation of telomeric repeat-containing RNA by acridine derivatives," RNA Biol., 2021, doi: 10.1080/15476286.2021.1899652.

[92] Y. Zhang et al., "Interaction of Quindoline derivative with telomeric repeat-containing RNA induces telomeric DNA-damage response in cancer cells through inhibition of telomeric repeat factor 2," Biochim. Biophys. ActaGen. Subj., vol. 1861, no. 12, pp. 3246-3256, Dec. 2017.

[93] C. Leonetti et al., "G-quadruplex ligand RHPS4 potentiates the antitumor activity of camptothecins in preclinical 
models of solid tumors," Clin. Cancer Res., vol. 14, no. 22, 2008, doi: 10.1158/1078-0432.CCR-08-0941.

[94] E. Salvati et al., "Telomere damage induced by the G-quadruplex ligand RHPS4 has an antitumor effect," J. Clin. Invest., vol. 117, no. 11, 2007, doi: 10.1172/JCI32461.

[95] A. Rizzo et al., "Identification of novel RHPS4-derivative ligands with improved toxicological profiles and telomere-targeting activities," J. Exp. Clin. Cancer Res., vol. 33, no. 1, 2014, doi: 10.1186/s13046-014-0081-x.

[96] E. Salvati et al., "A basal level of DNA damage and telomere deprotection increases the sensitivity of cancer cells to G-quadruplex interactive compounds," Nucleic Acids Res., vol. 43, no. 3, 2015, doi: 10.1093/nar/gkv006.

[97] R. Amato et al., "G-quadruplex stabilization fuels the ALT pathway in ALT-positive osteosarcoma cells," Genes (Basel)., vol. 11, no. 3, Mar. 2020, doi: 10.3390/GENES11030304.

[98] F. Berardinelli et al., "G-quadruplex ligand RHPS4 radiosensitizes glioblastoma xenograft in vivo through a differential targeting of bulky differentiated- and stem-cancer cells," J. Exp. Clin. Cancer Res., vol. 38, no. 1, Jul. 2019, doi: 10.1186/S13046-019-1293-X.

[99] F. Berardinelli, S. Siteni, C. Tanzarella, M. F. Stevens, A. Sgura, and A. Antoccia, "The G-quadruplex-stabilising agent RHPS4 induces telomeric dysfunction and enhances radiosensitivity in glioblastoma cells," DNA Repair (Amst)., vol. 25, pp. 104-115, Jan. 2015, doi: 10.1016/J.DNAREP.2014.10.009.

[100] M. Gunaratnam et al., "G-quadruplex compounds and cis-platin act synergistically to inhibit cancer cell growth in vitro and in vivo.," Biochem. Pharmacol., vol. 78, no. 2, pp. 115-122, Jul. 2009, doi: 10.1016/j.bcp.2009.03.018.

[101] G. Zhou et al., "Telomere targeting with a novel G-quadruplex-interactive ligand BRACO-19 induces T-loop disassembly and telomerase displacement in human glioblastoma cells.," Oncotarget, vol. 7, no. 12, pp. 1492514939, Mar. 2016, doi: 10.18632/oncotarget.7483.

[102] Y.-T. Fu, B. R. Keppler, J. Soares, and M. B. Jarstfer, "BRACO19 analog dimers with improved inhibition of telomerase and hPot 1.," Bioorg. Med. Chem., vol. 17, no. 5, pp. 2030-2037, Mar. 2009, doi: 10.1016/j.bmc.2009.01.015.

[103] D. Hasegawa, S. Okabe, K. Okamoto, I. Nakano, K. Shin-Ya, and H. Seimiya, “G-quadruplex ligand-induced DNA damage response coupled with telomere dysfunction and replication stress in glioma stem cells," Biochem. Biophys. Res. Commun., vol. 471, no. 1, pp. 75-81, Feb. 2016, doi: 10.1016/J.BBRC.2016.01.176.

[104] N. Temime-Smaali, L. Guittat, A. Sidibe, K. Shin-Ya, C. Trentesaux, and J. F. Riou, "The G-quadruplex ligand telomestatin impairs binding of topoisomerase III $\alpha$ to G-quadruplex-forming oligonucleotides and uncaps telomeres in ALT cells," PLoS One, vol. 4, no. 9, Sep. 2009, doi: 10.1371/JOURNAL.PONE.0006919.

[105] D. Gomez et al., "The G-quadruplex ligand telomestatin inhibits POT1 binding to telomeric sequences in vitro and induces GFP-POT1 dissociation from telomeres in human cells," Cancer Res., vol. 66, no. 14, pp. 6908-6912, Jul. 2006, doi: 10.1158/0008-5472.CAN-06-1581.

[106] N. Binz, T. Shalaby, P. Rivera, K. Shin-ya, and M. A. Grotzer, "Telomerase inhibition, telomere shortening, cell growth suppression and induction of apoptosis by telomestatin in childhood neuroblastoma cells.," Eur. J. Cancer, vol. 41, no. 18, pp. 2873-2881, Dec. 2005, doi: 10.1016/j.ejca.2005.08.025.

[107] T. Tauchi et al., "Activity of a novel G-quadruplex-interactive telomerase inhibitor, telomestatin (SOT-095), against human leukemia cells: involvement of ATM-dependent DNA damage response pathways.," Oncogene, vol. 22, no. 34, pp. 5338-5347, Aug. 2003, doi: 10.1038/sj.onc.1206833.

[108] T. Tauchi, J. H. Ohyashiki, and K. Ohyashiki, "Telomerase inhibition combined with other chemotherapeutic reagents to enhance anti-cancer effect.," Methods Mol. Biol., vol. 405, pp. 181-189, 2007, doi: 10.1007/978-1-60327070-0_14.

[109] D. Muoio et al., "Naphthalene diimide-derivatives G-quadruplex ligands induce cell proliferation inhibition, 
mild telomeric dysfunction and cell cycle perturbation in U251MG glioma cells," FEBS J., vol. 285, no. 20, pp. 541 3769-3785, Oct. 2018, doi: 10.1111/FEBS.14628.

[110] F. Doria et al., "Dyads of G-Quadruplex Ligands Triggering DNA Damage Response and Tumour Cell Growth Inhibition at Subnanomolar Concentration," Chem. - A Eur. J., vol. 25, no. 47, 2019, doi: 10.1002/chem.201900766.

[111] S. A. Ohnmacht et al., "A G-quadruplex-binding compound showing anti-tumour activity in an in vivo model for pancreatic cancer.," Sci. Rep., vol. 5, p. 11385, Jun. 2015, doi: 10.1038/srep11385.

[112] M. Micco et al., "Structure-based design and evaluation of naphthalene diimide G-quadruplex ligands as telomere targeting agents in pancreatic cancer cells," J. Med. Chem., vol. 56, no. 7, pp. 2959-2974, Jun. 2013, doi: 10.1021/jm301899y.

[113] F. Berardinelli, E. Coluzzi, A. Sgura, and A. Antoccia, "Targeting telomerase and telomeres to enhance ionizing radiation effects in in vitro and in vivo cancer models.," Mutat. Res. Rev. Mutat. Res., vol. 773, pp. 204-219, Jul. 2017, doi: 10.1016/j.mrrev.2017.02.004.

[114] S. Müller et al., "Pyridostatin analogues promote telomere dysfunction and long-term growth inhibition in human cancer cells.," Org. Biomol. Chem., vol. 10, no. 32, pp. 6537-6546, Aug. 2012, doi: 10.1039/c2ob25830g.

115] V. Casagrande et al., "N-cyclic bay-substituted perylene g-quadruplex ligands have selective antiproliferative effects on cancer cells and induce telomere damage," J. Med. Chem., vol. 54, no. 5, 2011, doi: 10.1021/jm1013665.

[116] M. Franceschin et al., "Aromatic Core Extension in the Series of N-Cyclic Bay-Substituted Perylene GQuadruplex Ligands: Increased Telomere Damage, Antitumor Activity, and Strong Selectivity for Neoplastic over Healthy Cells," ChemMedChem, vol. 7, no. 12, 2012, doi: 10.1002/cmdc.201200348.

[117] Y. Zhang et al., "Interaction of Quindoline derivative with telomeric repeat-containing RNA induces telomeric DNA-damage response in cancer cells through inhibition of telomeric repeat factor 2," Biochim. Biophys. Acta Gen. Subj., vol. 1861, no. 12, pp. 3246-3256, Dec. 2017, doi: 10.1016/J.BBAGEN.2017.09.015. 